die Gattungen (nicht aber meine Art mit der Jordanschen) zusammen.

X, 3013 - Nemophas cyanescens Jord. Nov. Zool., V, 1898, 419 ist, worauf mich der Autor freundlichst aufmerksam macht $=$ (atrocyaneus Hllr.) Tijdschr. voor Ent., LVII, 1919, 100.

39, 417 - Sclethrus newmani Cherr. von Mindanao (nicht Maldonado!) $=$ (Neocollyrodes g. n. macgregori W. Schultze) Ph. Journ. Sc. XVI, Nr. 2, 1920, 196, Taf. 1, Fig. 2. Die Art liegt mir mit aus Luzon, I os Baños, ges. 1912 von Prof. C.F. B aker, vor.

\title{
Ein neuer Othnius von Palawan. (Col.)
}

\author{
Von F. Borehmann, Hamburg.
}

(Mit I Textfigur.)

Eben nach dem Drucke einer umfassenden Ủbersicht über die Familie der Othniidae sandte mir Herr Kustos S. Schenkling die nachfolgende neue Art:

Othnius ochripes nov. spec. Länge: $2,6 \mathrm{~mm}$. — Form wie acutedentatus Bm., ziemlich gewölbt; mäßig glänzend; ziemlich lang, anliegend weißlich behaart; dunkel rotbraun, Beine samt den Füßen und den Hüften hell braungelb, Kopf und Halsschild dunkel bronzefarbig, Halsschild mit rötlichen Vorderecken; Schildchen

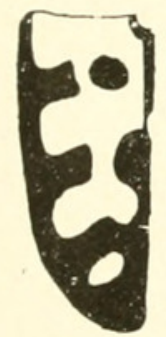
dunkel; Flügeldecken hell gelbbraun, Naht schmal, Seitenrand breiter, drei Querbinden, deren beiden vorderen in je zwei Flecke aufgelöst sind und die Spitze dunkelbraun, die äußeren Flecke sind mit dem Rande verbunden, der innere Fleck der vorderen Binde steht frei und ist rundlich, der Fleck der 2. Binde hängt mit der Naht zusammen und ist halbrund; Fühler rotbraun, Keule wenig dunkler. Kopf gewöhnlich, ziemlich dicht und stark punktiert; Mundteile gewöhnlich, hellbraun; Fühler gewöhnlich, den Hinterrand des Halsschildes nicht erreichend, 3. Glied fast doppelt so lang wie das 2., 7. und 8. kaum quer, Glieder der Keule gleich lang; Augen gewöhnlich; Halsschild fast so lang wie breit, wenig schmäler als der Kopf mit den Augen, ziemlich gewölbt, sehr dicht und grob punktiert, Zwischenräume viel schmäler als die Punkte, vor der Basis ein nach vorn offener, bogenförmiger Eindruck, Behaarung von der Nitte nach außen gekämmt, Halsschildseiten fast geradlinig ziemlich bedeutend gegen die Basis verengt, mit 4 ziemlich kleinen, voneinander gleich weit entfernten Zähnchen, Ecken der Basis scharf rechtwinklig, Basiswinkel so breit wie die Abstände der Entomol. Mitteilungen $\mathrm{X}$. 
Zähnchen, Basis fast gerade, so breit wie eine Flügeldecke, Vorderecken abgerundet und stark nach unten gezogen. Schilder gewöhnlich. Flügeldecken gewöhnlich, $2 \frac{1}{2}$ mal so lang wie der Halsschild, Seiten sanft gerundet, gleichmäßig von der Basis zur Spitze verengt, Schulterbeule stark, Behaarung an der Basis und Naht nach hinten, sonst nach außen gelagert, Punktierung dicht und ziemlich stark, weniger grob als die des Halsschildes, Zwischenräume etwa so breit wie ein Punkt, gegen die Spitze feiner; Unterseite und Beine gewöhnlich.

1 Stück von N. Palawan, Binaluan XI -XII, 1913 (leg. G. B oet tcher) im Deutschen Entomol. Institut (Dahlem).

Die Art unterscheidet sich von acutedentatus Bm., der sie sehr ähnlich ist, leicht durch die viel gröbere Punktierung, die Bezahnung des Halsschildseitenrandes und die abweichende Färbung, besonders der Beine, und die längeren Fühler.

\section{Sammelgeräte. (Ein Vorschlag.)}

Von Dr. rer. nat. H. Andreae, Kapstadt.

(Mit 3 Textfiguren.)

Die Käferfauna der höheren Berge in der Umgegend von Kapstadt ist noch recht wenig bekannt; wer sie erforschen will, muß Proviant, Ausrüstung und Ausbeute auf den eigenen Schultern fortschaffen, und das haben nur wenige getan. Es liegt auf der Hand, daß unter solchen Umständen der Erfolg zum großen Teil von der Beschaffenheit der Sammelgeräte abhängt; sie müssen unter den verschiedensten Verhältnissen verwendbar sein, dabei möglichst wenig wiegen und möglichst wenig Raum einnehmen. So ergaben sich verschiedene Änderungen.

1. Käfersieb. Statt des Ringes mit Ausschnitt und Handgriff ein U-förmiger Bügel aus Federstahl von $4 \mathrm{~mm}$ Dicke, an den Enden zu Ösen gebogen, zwischen denen eine starke Schnur gespannt ist. Im Bogen als Handgriff und Versteifung ein leichtes Brett mit Hohlkehle am Außenrand, an drei Stellen durch in schwachen Kerben liegende Drahtwicklungen gehalten. Der runde Siebboden auswechselbar, außen mit Band umnäht oder mit Schnur umwickelt; von unten gehalten durch einen in den Siebbeutel eingenähten Ring von $1 \mathrm{~cm}$ geringerem Durchmesser mit Drahtkreuz, von oben (2 cm über diesem) durch eine Schnur auf der Außenseite des Beutels, die durch die Öffnungen eines in Abständen von $10 \mathrm{~cm}$ durchlochten Leinenstreifens gezogen ist. Unterer Handgriff eine starke Bandschleife. Unterhalb des Siebbodens ist der Beutel konisch verengt und endigt in einem $2 \mathrm{~cm}$ langen Stutzen, in den oben und unten ein Drahtring eingenäht 


\section{$2 \mathrm{BHL}$ Biodiversity Heritage Library}

1921. "Ein neuer Othnius von Palawan (Col.)." Entomologische Mitteilungen 10, 198-199. https://doi.org/10.5962/bhl.part.3326.

View This Item Online: https://www.biodiversitylibrary.org/item/39843

DOI: https://doi.org/10.5962/bhl.part.3326

Permalink: $\underline{\text { https://www.biodiversitylibrary.org/partpdf/3326 }}$

\section{Holding Institution}

Smithsonian Libraries

\section{Sponsored by}

Smithsonian

\section{Copyright \& Reuse}

Copyright Status: NOT_IN_COPYRIGHT

This document was created from content at the Biodiversity Heritage Library, the world's largest open access digital library for biodiversity literature and archives. Visit BHL at https://www.biodiversitylibrary.org. 